University of Nebraska - Lincoln

DigitalCommons@University of Nebraska - Lincoln

\title{
The Over-Claiming Technique: Measuring Self-Enhancement Independent of Ability
}

\author{
Delroy L. Paulhus \\ University of British Columbia, dpaulhus@psych.ubc.ca \\ Peter D. Harms \\ University of Nebraska - Lincoln, pharms@gmail.com \\ M. Nadine Bruce \\ University of British Columbia \\ Daria C. Lysy \\ University of British Columbia
}

Follow this and additional works at: https://digitalcommons.unl.edu/leadershipfacpub

Part of the Management Sciences and Quantitative Methods Commons

Paulhus, Delroy L.; Harms, Peter D.; Bruce, M. Nadine; and Lysy, Daria C., "The Over-Claiming Technique: Measuring Self-Enhancement Independent of Ability" (2003). Leadership Institute Faculty Publications.

12.

https://digitalcommons.unl.edu/leadershipfacpub/12

This Article is brought to you for free and open access by the Leadership Institute at DigitalCommons@University of Nebraska - Lincoln. It has been accepted for inclusion in Leadership Institute Faculty Publications by an authorized administrator of DigitalCommons@University of Nebraska - Lincoln. 
Published in Journal of Personality and Social Psychology 84:4 (2003), pp. 890-904; doi: 10.1037/0022-3514.84.4.890 Copyright (C) 2003 American Psychological Association. Used by permission. "This article may not exactly replicate the final version published in the APA journal. It is not the copy of record." http://www.apa.org/journals/jpsp/

This research was supported by a grant to Delroy L. Paulhus from the Social Sciences and Humanities Research Council of Canada. We thank Sam Gosling, Rick Robins, and Jennifer Campbell for their helpful comments on an earlier version. We thank David Strasser, Elaine Stouffer, Georgia Stavrides, and Steve Moon for their assistance with data collection.

\title{
The Over-Claiming Technique: Measuring Self-Enhancement Independent of Ability
}

\author{
Delroy L. Paulhus, P. D. Harms, M. Nadine Bruce, and Daria C. Lysy \\ Department of Psychology, University of British Columbia \\ P. D. Harms is now at the Department of Psychology, University of Illinois. \\ M. Nadine Bruce is now at Capilano College, North Vancouver, British Columbia, Canada. \\ Daria C. Lysy is now at the College of Education and Human Development, University of Maine. \\ Corresponding author - D. L. Paulhus, Department of Psychology, University of British Columbia, \\ 2136 West Mall, Vancouver, British Columbia V6T 1Z4 Canada; email dpaulhus@psych.ubc.ca
}

\begin{abstract}
Overclaiming is a concrete operationalization of self-enhancement based on respondents' ratings of their knowledge of various persons, events, products, and so on. Because $20 \%$ of the items are nonexistent, responses can be analyzed with signal detection formulas to index both response bias (over-claiming) and accuracy (knowledge). Study 1 demonstrated convergence of over-claiming with alternative measures of self-enhancement but independence from cognitive ability. In Studies 2-3, the validity of the overclaiming index held even when respondents were (a) warned about the foils or (b) asked to fake good. Study 3 also showed the utility of the over-claiming index for diagnosing faking. In Study 4 , the over-claiming technique was applied to the debate over the adaptive value of positive illusions.
\end{abstract}

The tendency for some people to self-enhance when describing themselves remains a concern for researchers who rely on questionnaires and other self-report methods. Accurate identification of such individuals has been a longstanding goal of psychometricians, but the search for a valid indicator has been disappointing (for reviews, see Baer, Rinaldo, \& Berry, in press; Paulhus, 1991, 2002). Few researchers completely ignore the issue, although many doubt the utility of currently available measures. The three approaches that have attracted the most attention as well as criticism are (a) social desirability scales, (b) intrapsychic measures, and (c) discrepancy measures.

\section{Contemporary Measures of Self-Enhancement}

\section{Measures of Socially Desirable Responding}

The most common approach has been to measure individual differences in socially desirable responding (SDR) via questionnaire. Such instruments pose questions designed to identify individuals who exaggerate their positive and minimize their negative qualities. Among the most popular are the Marlowe-Crowne scale (Crowne \& Marlowe, 1964), the Edwards Social Desirability scale (A. L. Edwards, 1957), and the Balanced Inventory of Desirable Responding (Paulhus, 1984, 1991). Although SDR scales are widely used, it is difficult to verify that these self-report instruments truly capture inflation of self-descriptions (Hogan \& Nicholson, 1988; Paulhus, 2002). The key issue is the difficulty of distinguishing valid personality content from desirable responding (Block, 1965; McCrae \& Costa, 1983; Paulhus, 2002). For example, how do we know whether someone who denies ever swearing-a typical SDR item - is being honest or not?

\section{Intrapsychic Measures}

The tendency for people to rate themselves more positively than they rate others is known as the better than average effect (Alicke, 1985). Some researchers have inferred individual differences in self-enhancement from the degree to which individuals exhibit the better than average effect. Brown (1986), for example, asked participants to compare themselves with the average other person across a variety of characteristics. The sum of such ratings was used to index an individual's self-enhancement. As with SDR scales, this approach has been criticized on the grounds that no indicator of external reality is involved (Colvin, Block, \& Funder, 1995; John \& Robins, 1994).

Other intrapsychic measures include Krueger's (1998) idiographic technique based on the correlation between an individual's self-ascribed traits and his or her ratings of the desirability of those traits. Its independence from other measures is intriguing (Sinha \& Krueger, 1998) and warrants further research. The most recent intrapsychic measure is the "superiority index," based on the difference between self-ratings and ratings of others (Bond, Kwan, \& Li, 2000). These authors noted, however, that their difference score index is not ideal because it masks critical information about the two constituent components.

\section{Criterion Discrepancy Measures}

These measures index self-enhancement by the degree to which a respondent's self-ratings are more positive than warranted by a credible criterion (Funder \& Colvin, 1997; Robins \& John, 1997). Criterion measures fall into two categories: 
operational criteria and social consensus. Operational criteria are unambiguous, concrete indicators of performance. For example, intelligence test scores may be used as a criterion for self-rated intelligence (Paulhus, Lysy, \& Yik, 1998), grades as a criterion for scholastic ability ratings (Robins \& Beer, 2001), and videotaped social behavior as a criterion for personality ratings (Gosling, John, Craik, \& Robins, 1998). Social consensus criteria rely on the assumption that the mean rating of a set of informed observers is the best estimate of social reality (e.g., Funder, 1995; Hofstee, 1994; Kenny, 1994; Kwan, John, Kenny, Bond, \& Robins, in press). Given their face validity and logic of computation, criterion discrepancy measures appear to be the most convincing operationalization of self-enhancement to date.

Such measures are not without drawbacks, however. First, there are legitimate disputes about whether discrepancies should be measured with raw difference scores or the residual self-rating after the criterion is removed (Zumbo, 1999). Others have argued that neither procedure avoids the controversial problem of unreliability of difference scores (J. R. Edwards, 1995). The practical difficulties of the discrepancy techniques are also a significant deterrent. The researcher has to collect two measures: a self-perception measure and an objective criterion. Moreover, collection of the latter measure, whether it involves coding videotapes, administering ability tests, or estimating social consensus, is always a complicated and timeconsuming endeavor. An ideal approach would retain the objectivity of discrepancy measures yet permit assessment in a single self-report measure. The over-claiming technique is a promising candidate.

\section{The Over-Claiming Technique}

Over-claiming is the tendency to claim knowledge about nonexistent items. The term originated with Phillips and Clancy (1972), who developed an ad hoc index for use in a consumer survey. They asked respondents to rate their familiarity with a set of consumer-related items; in truth, none of the items actually existed. Hence, any claim of familiarity with the items suggested self-serving distortion. The sum of rated familiarities with these nonexistent items constituted the index of over-claiming.

Surprisingly little use has been made of the over-claiming approach suggested by Phillips and Clancy (1972). Stanovich and Cunningham (1992) asked respondents to rate their familiarity with a list of authors that included 50\% foils to control for desirable responding. The claim rate for foils was subtracted from the claim rate for real authors to obtain an unbiased estimate of author knowledge. However, neither of these research teams analyzed the tendency to claim foils as a variable in its own right. The only such study was by Randall and Fernandes (1991), who used overclaiming as a control for bias in self-reports of unethical behavior. Like Phillips and Clancy, they scored only nonexistent items. Their over-claiming index (the sum of ratings of nonexistent items) showed significant positive correlations with SDR as measured by the Balanced Inventory of Desirable Responding (BIDR; Paulhus, 1991). This lone finding in the literature suggests that the over-claiming approach may have potential for indexing response biases in self-reports of personality.

\section{The Over-Claiming Questionnaire (OCQ)}

To systematize this approach, we developed a comprehensive self-report measure of academic and everyday knowledge (Paulhus \& Bruce, 1990). The items were culled from comprehensive lists provided by Hirsch (1988) in the appendix of his book, Cultural Literacy. We partitioned the items into 10 categories: historical names and events, fine arts, language, books and poems, authors and characters, social science and law, physical sciences, life sciences, popular culture, and current consumer products.

On that version of the questionnaire, titled the Over-Claiming Questionnaire-150, or OCQ-150, respondents rate their familiarity with 150 items broken down into 10 categories. Each item is rated on a 7-point scale ranging from 0 (never heard of it) to 6 (know it very well). One sample page from the questionnaire is presented in the Appendix. Within each category, 3 out of every 15 items are foils, that is, they do not actually exist. Hence, any degree of claimed knowledge about them constitutes over-claiming. The three foils were created to appear to be plausible members of the same category as the 12 real items. On the total of 150 items, then, a respondent could falsely claim knowledge of 30 foil items distributed over a variety of topics.

\section{Signal Detection Scoring}

Given the nature of the OCQ response categories-claims to recognize existent and nonexistent items-signal detection analysis (SDA) seemed to be the ideal analytic approach (Swets, 1964). The approach applies when responses fall into one of four categories: (a) hits, claims that existent items are familiar; (b) false alarms, claims that nonexistent items are familiar; (c) misses, claims that existent items are unfamiliar; and (d) correct rejections, claims that nonexistent items are unfamiliar. From the signal detection perspective, previous researchers have used only false alarms to index over-claiming: That is, they tallied claims of only the nonexistent items. By using only false alarms, however, one discards useful information from the existent items. After all, respondents who over-claim should do so on existent as well as nonexistent items (i.e., they will assign a higher rating than is warranted). SDA, however, ensures that such information is not wasted. SDA exploits all responses in the calculation of separate indexes for accuracy and response bias.

\section{Knowledge Accuracy}

Accuracy is indexed by the number of hits relative to the number of false alarms. That construct has a variety of operationalizations, the most well-known being $d^{\prime}$ (Humphreys \& Swets, 1991). An accurate individual, then, is not the one scoring the most hits but the one showing the best ability to discriminate between existent and nonexistent items. When scored on the OCQ responses, we call this OCQ accuracy.

\section{Response Bias}

In SDA, response bias is the stylistic tendency to say "Yes, I recognize that item" versus "No, I don't recognize that item." This bias is assumed to influence ratings of both existent and nonexistent items. Numerous operationalizations of bias have been derived from SDA (Macmillan \& Creelman, 1991). Unfortunately, the most popular index, beta, has statistical proper- 
ties that rule it out as useful for analyzing OCQ data (Paulhus \& Petrusic, 2002). ${ }^{1}$ The raw false-alarm rate is an appealing choice because it provides the most face-valid operationalization of over-claiming. Unfortunately, this index often correlates substantially with hit rate, thereby confounding the measurement of over-claiming with accurate reports of knowledge.

Instead, we opted for criterion location (c) as our index of response bias. Index $c$ is a standardized statistical estimate of how strong the sense of familiarity has to be for a respondent to say "Yes, I am familiar with that item" (Macmillan \& Creelman, 1991). ${ }^{2}$ The values of $c$ correspond roughly to the mean of the hit rate and the false-alarm rate. When scored on the OCQ responses, we call this index OCQ bias.

\section{Summary}

We used SDA to develop operationalizations of the concepts of over-claiming and knowledge on the basis of participants' familiarity ratings on the OCQ. Specifically, over-claiming was operationalized with the OCQ bias index and general knowledge with the OCQ accuracy index.

\section{Preliminary Study}

In a small preliminary study, the OCQ-150 was administered to a sample of 44 students (Paulhus \& Bruce, 1990). Analyses revealed that (a) the OCQ accuracy index was correlated .48 with scores on an IQ test and (b) the OCQ bias index was correlated 40 with self-perceptions of general knowledge. In addition, 8-week test-retest correlations of the accuracy index $(r$ $=.76, p<.01)$ and bias scores $(r=.80, p<.01)$ revealed a reasonable temporal stability.

When scored separately by knowledge domain, the 10 bias scores showed substantial intercorrelations (Paulhus \& Bruce, 1990). This consistency suggested to us that the same individuals were over-claiming across all domains. We also found that reversing the direction of the rating scale of one domain had no effect on its intercorrelations with other domain scores: Hence, we ruled out the possibility that over-claiming was simply some sort of acquiescent response bias (e.g., Knowles \& Condon, 1999; Wiggins, 1973).

Although the sample size was small $(N=44)$, these preliminary results appeared promising enough to pursue the use of OCQ accuracy and OCQ bias as measures of knowledge and over-claiming. Our subsequent efforts yielded the four larger studies presented in this report.

\section{Overview of Present Studies}

In Study 1, we collected a variety of convergent validities for both the knowledge and over-claiming indexes. The overclaiming index was also pitted against its strongest competitor, the criterion discrepancy measure. In Study 2, the robustness of the over-claiming index was evaluated across conditions where respondents were warned or not warned of the presence of foils. In Study 3, the robustness of the over-claiming index was evaluated under faking conditions. In Study 4, the utility of the over-claiming index was evaluated by testing its ability to provide leverage on the debate over the TaylorBrown positive illusions hypothesis.

\section{Study 1. Convergent and Comparative Validity}

We began by evaluating the respective convergent and discriminant validities of the over-claiming index (OCQ bias) and the knowledge index (OCQ accuracy). The validity of the OCQ bias index would be supported by convergent correlations with alternative measures of self-enhancement, including established trait measures. Specifically, OCQ bias should predict scores on the Narcissistic Personality Inventory (Raskin \& Hall, 1979) and the Self-Deceptive Enhancement (SDE) scale (Paulhus, 1991). Similarly, OCQ accuracy scores should predict scores on a measure of crystallized intelligence (Horn \& Cattell, 1966).

The design of Study 1 entailed the collection of questionnaire responses and mutual behavior ratings from members of 30 small groups after a series of group meetings. Analysis of those self-report and peer ratings along with scores on a brief IQ test permitted the prediction of a variety of alternative measures of self-enhancement.

\section{Method}

\section{Participants}

Participants were 137 students, 60 male and 77 female, enrolled in a 3rd-year psychology course at a large Canadian university. After the course was completed, they were asked if their data could be analyzed for research purposes. All agreed.

\section{Instruments}

Trait self-enhancement measures - The Narcissistic Personality Inventory (NPI; Raskin \& Hall, 1979) is a well-validated measure of normal narcissism. The 40-item forced-choice version shows strong convergent validity with clinical judgment and self-enhancement behavior (e.g., Emmons, 1987; Raskin \& Terry, 1988; Rhodewalt \& Morf, 1995). Among its most robust behavioral correlates is self-enhancement (e.g., John \& Robins, 1994; Gosling et al., 1998; Paulhus, 1998). A sample narcissist option is "I would make a great leader"; a sample non-narcissist option is "I am just an average person."

The BIDR (Paulhus, 1991; 2002) contains sixty 7-point Likert scales. Three subscales are scored as follows: (a) the SDE scale (20 items), designed to tap honestly held exaggeration of one's positive attributes; (b) the Self-Deceptive Denial (SDD) scale (20 items), designed to tap exaggerated tendencies to disavow one's negative attributes; and (c) the Impression Management (IM) scale (20 items) designed to tap positive self-presentation targeted at a public audience. The intercorrelations of the SDE scale with the SDD and IM scales range from .20 to .35 , whereas the latter two scales often show high intercorrelations (Paulhus, 2002). Only extreme responses (i.e., 6 or 7, after rekeying) are scored. The rationale is that extreme responses are more likely to indicate distortion (Paulhus, 1984).

Finally, the questionnaire package included the Self-Monitoring scale (Snyder, 1974), a 25-item true-false measure designed to tap a propensity toward impression management. Recent reviews

\footnotetext{
1 Paulhus and Petrusic (2002) provided details on this point. The standard formula for beta stipulates that bias scores approach neutral as $d^{\prime}$ decreases. This quality is appropriate for certain applications of SDA but certainly not for individual differences. We require an index that yields meaningful values even for individuals with poor knowledge of a topic.

2 This interpretation required that $c$ be reversed so that high scores indicate affirmative answers.
} 
are available in Graziano and Waschull (1995) and Gangestad and Snyder (2000).

Self and peer ratings - Participants rated all their group members including themselves on twenty-five 15-point items. Five items related to cognitive ability (e.g., "intelligent," "creative"). Fifteen bipolar adjectives derived from McCrae and Costa (1987) were used to tap the Big Five personality traits (i.e., three each). Five other peer-rating items addressed observed self-enhancement, including "brags a lot" and "is egotistical." Instructions warned that no ties were allowed: That is, no two members were to be assigned the same number on any one scale.

Cognitive ability - The Wonderlic IQ test (Wonderlic, 1977) was chosen to assess global cognitive ability. Included are items sampled from verbal, quantitative, and analytic domains. Although a 12-min time limit is imposed, the Wonderlic behaves more like a power test than a speeded test because the items are presented in ascending order of difficulty (McKelvie, 1989).

The measure is very popular in applied settings because of its ease of administration and comprehensive norms combined with ample reliability and validity evidence. Expert reviews have been favorable (e.g., Schmidt, 1985; Schoenfeldt, 1985). Test-retest reliabilities range from .82 to .94 (Wonderlic, 1992). Previous studies in college populations have demonstrated its predictive validity for college grades (McKelvie, 1989), self-ratings of intelligence (Paulhus et al., 1998), and supervisory rankings (Wonderlic, 1992).

\section{Procedure}

Prior to being assigned to groups, all participants completed a package of trait questionnaires. Next, participants were organized into 30 groups of strangers: 17 of the groups had 5 members and the remaining 13 groups had 4 members. Group assignments were random with the constraint of heterogeneity with regard to gender and ethnicity. The groups met weekly for 20 min over 7 consecutive weeks. Participants were requested to avoid interaction with fellow group members outside of official meetings. No instructions were given regarding leadership within the groups, but weekly instructions advised that each individual was to participate in the discussion.

Before each meeting, a discussion topic was assigned. Topics had been selected to encourage engagement with class readings and lecture topics and to provide opportunity for a variety of personality dimensions to be brought into play. The topics, in chronological order, were descriptions of families' or friends' personalities, verbal and quantitative problem solving, positive and negative qualities of the self, worries and concerns, creative and absorbing experiences, social issues, and Allport's characteristics of a well-adjusted person.

After the final meeting, participants were given a rating sheet in an envelope and were asked to return the completed sheet to the instructor sealed in an envelope at the next class session. The sheets asked the participant to rate the overall attributes of each member of the discussion group, including themselves, on a total of 25 items.

\section{Results}

As in all four studies presented here, gender differences, when found, were small and inconsistent. Therefore male and female participants were pooled in all of our analyses.

\section{OCQ Indexes}

The accuracy and bias indexes were calculated from the OCQ responses using standard signal detection formulas (Macmil- lan \& Creelman, 1991). Indexes were calculated at each of the six cutoffs on the 0-6 rating scale (i.e., 0, 1, 2, 3, 4, and 5). The hit rate was the proportion of the 120 real items on which the respondent gave a rating above the cutoff. Similarly, the falsealarm rate was the corresponding proportion of the 30 foils on which the respondent gave a rating above the cutoff. The cutoff was first set between ratings of 0 and 1, yielding an overall hit rate of .44 and a false-alarm rate of .25 . From the hit and false-alarm proportions, two indexes were calculated for each respondent: The accuracy index was $d^{\prime}$, and the bias index was the criterion location $c .^{3}$ (For more detail on the choice of indexes, see Paulhus \& Petrusic, 2002.) These calculations were repeated for the other five cutoffs, and the six values of $c$ were averaged to get the final value of OCQ bias for each participant. A similar procedure was followed to calculate OCQ accuracy. The intercorrelation between OCQ accuracy and bias was .21.

\section{Convergent Validities}

Table 1 presents the associations of the OCQ accuracy and bias measures with a variety of relevant criterion measures. In each case, the criterion was regressed simultaneously on both accuracy and bias. The OCQ accuracy index shows a significant association (here, a standardized regression coefficient) with its criterion - scores on the IQ test. The OCQ bias index also shows significant associations with its two criterion measures - the NPI and the SDE - but not with the IM, SDD, or Self-Monitoring scales.

\section{Other Criterion Measures}

The rating index for cognitive ability (five items) yielded alpha values of .73 for self ratings and .84 for peer ratings. The rating index for observed self-enhancement (five items) yielded an alpha of .72.

We then constructed two discrepancy measures of selfenhancement. The first was ability enhancement: the discrepancy between self-reports of intelligence and scores on a standard IQ test. The discrepancy score was calculated as the residual of the self-rating index after IQ was removed with regression.

The second discrepancy measure was personality enhancement. First, self-enhancement was calculated on three-item composites of each of the Big Five factors. For each factor, a discrepancy score was calculated as the residual of the self-rating composite after the corresponding observer-rating composite was removed via regression. Two factors were extracted from the intercorrelations among these five discrepancy measures. As in previous work, Factor 1 was dominated by Extraversion and Openness and Factor 2 was dominated by Agreeableness. On the basis of similar results in Paulhus and John (1998), the first factor was interpreted as egoistic bias. This narcissistic form of self-enhancement is the central concern in the present report. Therefore, this first-factor score was used as our measure of personality enhancement.

Results are displayed in the final two rows of Table 1. As predicted, OCQ bias shows significant associations with both discrepancy measures of self-enhancement in performance, but OCQ accuracy does not.

3 Recall that responses were made on a 7-point scale, thus providing six cutoff values. The calculations of hits and false alarms culminating in $d^{\prime}$ and $c$ were repeated for the other five cutoffs. The final values of each index were the means across the six possible cutoffs. 
Table 1. Study 1: Associations of the Two Over-Claiming Questionnaire (OCQ) Indexes With Criterion Measures of Ability and Self-Enhancement

\begin{tabular}{lcc}
\hline & \multicolumn{2}{c}{$\begin{array}{c}\text { OCQ signal } \\
\text { detection indexes }\end{array}$} \\
\cline { 2 - 3 } Measure & Accuracy & Bias \\
\hline Cognitive ability (IQ test) & $.52^{* *}$ & $.17^{*}$ \\
Narcissism (NPI) & -.15 & $.35^{* *}$ \\
Self-Deceptive Enhancement (SDE) & .11 & $.30^{* *}$ \\
Self-Deceptive Denial (SDD) & -.15 & -.14 \\
Impression Management (IM) & -.15 & -.15 \\
Self-Monitoring Scale (SMS) & .14 & .11 \\
Discrepancy measures based on & & \\
$\quad$ discussion-group ratings & & $.25^{* *}$ \\
Ability enhancement & .13 & $.22^{* *}$ \\
Personality enhancement & .03 & \\
\hline
\end{tabular}

$N=137$. All values are the beta coefficients obtained when both bias and accuracy are entered in regression equations. NPI $=$ Narcissistic Personality Inventory.

${ }^{*} p<.05 ;{ }^{* *} p<.01$

\section{Head-to-Head Comparison}

The performance of these two discrepancy measures was then compared with that of OCQ bias with respect to their ability to predict various criterion measures of self-enhancement, including the NPI and SDE. The results are presented in Table 2.

Note that the validities of the OCQ bias measure are all higher than the corresponding validities for either discrepancy measure. In no case are the differences statistically significant, but it is evident that the OCQ bias index performs at least as well as either discrepancy measure.

\section{Discussion}

Study 1 has confirmed the dual function of over-claiming analysis. The accuracy and bias indexes scored from the OCQ knowledge ratings appear to be valid operationalizations of cognitive ability and self-enhancement, respectively. In particular, the convergent validities of both indexes-already promising in the preliminary study (Paulhus \& Bruce, 1990) - were confirmed in a large sample. The OCQ accuracy index showed a substantial association with an established measure of cognitive ability. Thus, the ability to distinguish real items from foils on the OCQ is indicative of a more general cognitive ability (for further evidence, see Paulhus \& Harms, in press).

More important for this report is the convergence of the OCQ bias index with a variety of established measures of self-enhancement. First, the OCQ bias index, but not the accuracy index, showed significant prediction of two self-enhancing traits, namely, narcissism and self-deceptive enhancement. In addition, the bias index converged with two sets of self-criterion discrepancy scores: One set comprised discrepancies between self and peer ratings of personality from discussion group members; the second set comprised discrepancies between self-rated intelligence and IQ scores. Together, the evidence justifies our argument that the OCQ bias measures a form of self-enhancement appropriately labeled over-claiming.
Table 2. Study 1: Comparative Predictive Efficacy of Over-Claiming Questionnaire (OCQ) Bias Index (Over-Claiming) Versus Two Discrepancy Measures of Self-Enhancement

\begin{tabular}{lccc}
\hline & $\begin{array}{c}\text { Over-claiming } \\
\text { measure } \\
\text { (OCQ bias) }\end{array}$ & $\begin{array}{c}\text { Intelligence } \\
\text { enhancement }\end{array}$ & Personality \\
\cline { 3 - 4 } $\begin{array}{l}\text { Criterion or outcome } \\
\text { enhancement }\end{array}$ & $.35^{* *}$ & $.31^{* *}$ & $.17^{*}$ \\
\hline $\begin{array}{l}\text { Narcissism (NPI) } \\
\begin{array}{l}\text { Self-Deceptive } \\
\text { Enhancement (SDE) }\end{array}\end{array}$ & $.30^{* *}$ & $.26^{* *}$ & $.17^{*}$ \\
$\begin{array}{l}\text { Observed } \\
\text { self-enhancement }\end{array}$ & $.35^{* *}$ & $.30^{* *}$ & $.26^{* *}$ \\
\hline
\end{tabular}

$N=137$. All values are beta regression coefficients. NPI $=$ Narcissistic Personality Inventory.

${ }^{*} p<.05 ;{ }^{* *} p<.01$

When the over-claiming and discrepancy measures were compared head-to-head in predicting various self-enhancement criteria, the over-claiming index performed at least as well. Of special interest is the fact that both were able to predict observer ratings of self-enhancement: Self-enhancing tendencies do not go unnoticed in discussion groups.

\section{Study 2. Effects of Warning Participants About Foils}

Study 1 confirmed the ability of the over-claiming index to predict trait measures of self-enhancement. But would this capability be undermined if participants were warned that the OCQ contains foils, that is, nonexistent items? Increasing accountability has been shown to decrease self-enhancement (Lerner \& Tetlock, 1999 4; Sedikides, Herbst, Hardin, \& Dardis, 2002). At the same time, accountability does not appear to change the relative tendency of narcissists to self-enhance to a greater degree than do non-narcissists (Robins \& John, 1997). Study 2 addresses both issues by directly manipulating narcissists' and non-narcissists' awareness of the presence of foils. We predict that (a) accountability will produce an overall reduction in over-claiming and (b) narcissists will continue to over-claim more than do non-narcissists.

\section{Method}

\section{Participants}

A total of 239 students (83 men and 156 women) participated for bonus marks in an undergraduate psychology course.

\section{Procedure}

The NPI and a 90-item version of the OCQ were administered to several large classes. The NPI was administered in standard questionnaire format. A cover sheet was distributed with spaces for demographic information and brief instructions about how to rate familiarity of the OCQ items. To keep all participants responding at the same pace, the OCQ items were presented one at a time on an overhead projector and simultaneously read aloud. 
The warning manipulation was effected by randomly varying the instruction statement appearing in bold at the bottom of the cover page. Participants in the warned condition were advised: "Note that some of the items in this inventory do not exist." Participants in the unwarned condition were advised: "Note that some of the items in this inventory are very difficult."

After completing all 90 items, participants were asked to turn over their answer booklet. All participants were then informed that some items did not exist and were asked if they recalled receiving the warning about the presence of nonexistent foils. Without turning over the sheet to check, they were asked to indicate on the back of the answer booklet whether they recalled seeing the warning.

\section{Results}

In the warned condition, only the participants who noticed the warning were included in the analyses. The intercorrelations of the OCQ accuracy and bias indexes did not differ between the warned condition $(r=.24)$ and the unwarned condition $(r$ $=.19$ ).

To maximize statistical power, the effect of narcissism level and warning condition were analyzed with regression rather than an analysis of variance (ANOVA). OCQ bias scores were regressed on NPI scores and the categorical variable representing experimental condition (warned $=1$, unwarned $=0$ ). An interaction term was created by multiplying the two predictors. The two main effects were force entered before the interaction term was entered as a predictor.

Narcissism showed a significant main effect $(\beta=.26), t(237)$ $=3.00, p<.01$. Specifically, narcissists over-claimed more than did non-narcissists. The main effect for condition was also significant $(\beta=.19), t(237)=2.19, p<.05$. Warned participants showed lower bias scores than unwarned participants. The interaction was not significant, suggesting that narcissists reduced their over-claiming no more and no less than did non-narcissists.

We also analyzed answers to the incidental question about whether participants had noticed the warning about foils. As above, OCQ bias was regressed on narcissism scores and condition. Not surprisingly, participants who were warned subsequently reported seeing the warning significantly more than did those who were unwarned $(\beta=.26), t(237)=3.71 p<$ .001 . This result provides a check for the warning manipulation. Narcissism also showed a significant main effect $(\beta=.19)$, $t(237)=2.25, p=.05$, with high narcissists claiming to have seen the warning more than did low narcissists. The interaction was not significant. The lack of interaction implies that narcissists claimed to have seen a warning whether or not they actually received it.

\section{Discussion}

Does warning participants about the foils have any effect on over-claiming? Study 2 suggests two effects. First is a reduced rate of over-claiming: Participants showed a more modest self-presentation when the possible embarrassment of claiming a nonexistent item was made salient. This malleability of self-enhancement is consistent with recent work using other operationalizations of self-enhancement (Alicke, Klotz, Breitenbecher, Yurak, \& Vredenburg, 1995; Krueger, 1998). In particular, the finding supports recent arguments that accountability deters self-enhancement (Sedikides et al., 2002).
Second, and more important for our primary message, the validity of the over-claiming index as a measure of self-enhancement was not compromised by the warning. Narcissists continued to over-claim more than did non-narcissists - and to the same degree. Apparently, the deterrent effects of accountability operate independently of the effects of trait levels of self-enhancement.

\section{Study 3. Effects of Deliberate Self-Presentation}

Study 1 established that the over-claiming index aligns with trait bias measures in student surveys, but such surveys tend to be low-demand conditions where participants' responses are largely forthright (Paulhus, 1991; Piedmont, McCrae, Reimann, \& Angleitner, 2000). Nonetheless, Study 2 showed that the threat of accountability reduces over-claiming. But will over-claiming increase when participants attempt a positive self-presentation? In Study 3, we manipulated self-presentation by administering the OCQ under two instructional sets: "respond honestly" and "make a good impression." Such instructions have been shown to be effective in altering the level of desirable responding in a systematic fashion (e.g., Holden, Wood, \& Tomashewski, 2001; Paulhus, Bruce, \& Trapnell, 1995; Wiggins, 1959).

Predicting the effects on individual differences is more complex. First, one must distinguish two aspects of positive self-presentation, namely, positive impression management and self-deceptive enhancement (e.g., Paulhus, 1984; Paulhus \& Reid, 1991). Using impression management, people often exaggerate their positive qualities in a conscious, deliberate fashion (for reviews, see Leary, 1995, or Schlenker \& Weigold, 1989). Under self-deception, people actually believe these exaggerations. Under low-demand conditions, narcissistic selfenhancement is self-deceptive (Paulhus, 1998). The results of Study 2 suggest, however, that narcissists are as susceptible as non-narcissists to situational demands.

Accordingly, we hypothesized two effects in these data. First, we expected that the mean over-claiming scores would track the demand for self-presentation across context. Second, we expected that the over-claiming rate of narcissists would remain higher than that of non-narcissists-even in the good impression condition. In other words, the validity of the overclaiming index should be sustained across conditions.

\section{Method}

\section{Participants}

A total of 76 undergraduate students participated as a class exercise in a 2nd-year undergraduate social personality class.

\section{Materials and Procedure}

In a within-subjects design, three instruments were administered under both honesty and good impression instructions. For this purpose, preliminary work was necessary to develop parallel forms of the three instruments. Two 30-item versions of the OCQ were developed by sampling items across four domains (literature, science, art, and history). Otherwise, the format was identical to the OCQ in Studies 1 and 2. The NPI was divided into two 20 -item versions. As in Study 1, it followed the standard forcedchoice format.

To index self-presentation, two parallel 14-item self-report measures were developed. They were designed to cover a broad 
range of personality and intellect: Therefore, each version was assigned two items for each factor of the Big Five Inventory (John \& Srivastava, 1999) and four cognitive ability items. The items were matched for desirability across versions. The rating scales ran from 1 (not at all) to 7 (very much). As a composite, the 14 items were labeled Positive Personality.

The administration procedure was presented as a class exercise in faking questionnaires. Participants were told that the responses would be totally anonymous. The two versions of each instrument were administered back to back. Preliminary instructions were forthright that participants were to respond honestly to the first version of each measure and to present an impression that was "as positive as possible" on the second version. Honest responses to the first version were encouraged by noting that, without responding honestly, subsequent scoring and feedback on their responses would be pointless. We chose this order because previous work indicated that faking first undermines the validity of subsequent honest responses (Holden, 1997).

Items were presented one by one on an overhead projector. The order of presentation was (a) the two 14-item personality-ability items, (b), the two 20-item versions of the NPI, and (c) the two 30 -item versions of the OCQ. All participants were specifically warned about the presence of foils on the OCQ.

\section{Results}

All instruments were scored such that high numbers represent a positive impression. The alpha reliabilities for the two conditions were reasonable for all variables: Positive Personality $(.76, .72)$, NPI $(.74, .80)$, and OCQ bias $(.78, .90)$. It may be surprising that the alphas were so high in the faking condition, because one would expect a severe restriction of range at the positive end of each measure. The size of these alphas suggests that participants used different but consistent faking styles: Some stuck with the most positive option whereas others selected a less-than-perfect option-perhaps to indicate that the best personality is not the most extreme.

The mean scores for each version of the three instruments were compared across honesty and faking conditions. All three measures showed significant increases in positivity. The 14-item Positive Personality index operated successfully as a manipulation check to confirm that participants had followed instructions, $t(74)=22.4, p<.01$. Our primary concern, the OCQ bias index, was significantly higher in the good impression condition than in the honest condition, $t(74)=4.5, p<.01$. This result supports our first hypothesis. ${ }^{5}$ The intercorrelation of the accuracy and bias indexes did not differ significantly between the honest condition $(r=.15)$ and the good impression condition $(r=.24)$.

Narcissism was measured by the 20 responses to the NPI items in the honest condition. These scores were used to predict OCQ bias scores in both the honest condition $(r=.21, p<$ $.05)$ and good impression condition $(r=.17, p<.05)$. To test whether these associations were different, we evaluated the interaction between condition and level of narcissism. A median split on the NPI was used to separate low from high narcissists. In a mixed ANOVA, OCQ bias scores in the two conditions were used as the within-subjects factor and the NPI categorization as the between-subjects factor.
The main effect for condition was significant, $F(1,74)=$ 23.87, $p<.01$, indicating that over-claiming was higher in the fake good condition. Also significant was the main effect for narcissism, $F(1,74)=5.61, p<.05$, indicating that narcissists over-claim more than non-narcissists. There was no sign of an interaction, $F(1,73)=1.73, p=.22$, supporting our prediction that the NPI validity should be sustained across conditions.

Although significant, these validities - that is, the associations between OCQ bias and NPI-do not appear impressive. Some readers may recognize the statistical factor that works against the significance of our predictions in this study: Specifically, the standard NPI and OCQ measures were shortened for use in the repeated-measures design. Thus, all the measures are systematically less reliable than the version typically administered (see Gulliksen, 1967). When corrected for the fact that the NPI was one half and the OCQ was one fifth its usual size, the correlations between the NPI and the OCQ bias index rise from .21 (honest condition) and .17 (good impression condition) to .34 (honest condition) and .29 (good impression condition). As effect sizes (Rosenthal \& Rosnow, 1991, p. 444), the latter values are in the moderate range.

\section{Discussion}

OCQ bias, our over-claiming index, appears to be sensitive to both trait and situational sources of self-enhancement. When trying to give a positive impression, participants showed a substantially higher rate of overclaiming. ${ }^{6}$ Even though all participants had been warned of the presence of foils, participants motivated to impress showed a clear tendency to exaggerate their claims of familiarity. This main effect suggests that the over-claiming scores can be useful in diagnosing demand for self-presentation across conditions.

At the same time, individual differences continue to play a role in predicting over-claiming. Within each condition, narcissists over-claimed more than did non-narcissists. Hence, the over-claiming index remains a valid indicator of trait selfenhancement regardless of the potentially disruptive impact of demand for self-presentation. Moreover, responses were anonymous in both conditions. One interpretation is that the narcissist's interpretation of self-enhancement instructions is to claim even more knowledge, whereas the non-narcissist's interpretation is that self-enhancement entails some modesty.

\section{Study 4. Application to the Positive Illusions Debate}

Taylor and Brown (1988) triggered an extended debate by postulating that positive illusions are adaptive. Among their three categories of illusions was that of overly positive self-perceptions, that is, an exaggerated belief that one possesses positive characteristics. Most of the subsequent literature, including our Study 4 , has dealt with that type of illusion.

The empirical basis for the Taylor-Brown postulate included demonstrations of the adaptive correlates of intrapsychic measures of self-enhancement. For example, Brown (1986) showed

5 Note that the OCQ was the only one of the three measures where participants were warned about possible detection of their faking (by mentioning the foils).

6 One criticism of this main effect for condition derives from the fixed order of honest then good impression. Recent work has shown that a repeat administration induces more desirable responses (Knowles, Coker, Scott, Cook, \& Neville, 1996). The effect size from those studies (roughly .15), however, is so small in comparison to ours (roughly .80 for our Positive Personality index), that a repetition order effect cannot explain our results. 
that susceptibility to the better-than-average effect predicted high self-esteem scores. A number of subsequent studies using discrepancy measures of self-enhancement, however, revealed maladaptive outcomes for self-enhancers (Colvin et al., 1995; John \& Robins, 1994). Still others have shown that that the valence and strength of association depends on the type of outcome measure as well as the type of self-enhancement measure (Bonanno, Field, Kovacevic, \& Kaltman, 2002; Paulhus, 1998; Roberts \& Robins, 2000; Robins \& Beer, 2001).

In Study 4, we evaluated the Taylor-Brown proposition using over-claiming as our operationalization of self-enhancement. A large sample of undergraduate students completed the OCQ along with several self-report measures of self-enhancement and adjustment. Adjustment ratings by knowledgeable informants were also collected.

To the extent that Taylor and Brown (1988) were correct, over-claiming should show a positive association with adjustment. To the extent that critics were correct (e.g., Colvin et al., 1995; John \& Robins, 1994), over-claiming should show a negative association with adjustment.

\section{Method}

\section{Subjects and Procedure}

Complete data were collected from 157 undergraduate students at a large Canadian university. The sample included 55 men and 102 women enrolled in an introductory psychology course. All participated for extra course credit.

Participants were assessed with regard to three sources of information. First, they completed a self-report inventory in a group administration. The inventory included (a) two standard questionnaire measures of adjustment, namely Rosenberg's (1965) SelfEsteem Scale and Block's (1989) revised Ego-Resiliency Scale, and (b) two standard measures of response bias, namely, the BIDR and the NPI. For descriptions of the latter two instruments, see Study 1 , above. The inventory also included self-ratings of cognitive ability and adjustment.

The second source of information was a take-home package that included the OCQ. Participants were asked to complete the package privately and return it to class for experimental credits. Instructions on the OCQ cover page advised participants to avoid asking anyone or looking up the items before they rated how familiar they looked: "We are simply doing a survey of what things students are familiar with and what things look unfamiliar."

The third source of information was a set of ratings completed by two knowledgeable informants. For a second extra credit, participants had to find two individuals who knew them well enough to complete the rating form privately and mail it back directly to the researchers. Roughly 52\% were friends, $40 \%$ were relatives, and $8 \%$ were others. Informants had to include their telephone numbers to permit verification that they had completed the ratings without any undue influence from the participant.

\section{Instruments}

Self-report adjustment - Three self-report measures were used. The Rosenberg Self-Esteem Scale is the most widely used measure of personal adjustment (Rosenberg, 1965). The concept emphasizes global self-worth as typified by such items as "On the whole, I am satisfied with myself." The alpha reliability was .92 in this sample. The revised Ego-Resiliency Scale (Block, 1989) was designed to measure resourceful adaptation to everyday stressors. Sample items are "I enjoy dealing with new and unusual situations" and "I get over anger reasonably easily." The construct validity of the instrument was supported in a review by Block and Kremen
(1996). The alpha reliability was .80 in our sample. Finally, adjustment was also indexed by a composite of six self-report items with an alpha value of .70 .

Informant-rated adjustment - Parallel with the self-report composite, adjustment was also scored from six items rated by informed observers. The items included "is well-adjusted" and "is often upset" (reverse scored). The alpha reliability of the six items was .86 in this sample.

Trait self-enhancement measures - The NPI, described above under Study 1, had an alpha reliability of .85 in this sample. The SDE and IM scales, also described under Study 1, had alpha reliabilities of .70 and .65 , respectively.

Discrepancy self-enhancement measure - The composite of five items measuring cognitive ability showed alphas of .78 for the self-report and .81 for the observer reports. A discrepancy measure was created from the composites of the self-report and informant-rated cognitive ability. The self-report was regressed on the informant report and the residual was isolated for use as a measure of ability self-enhancement.

\section{Results}

The three trait self-enhancement measures were regressed one at a time on the OCQ accuracy and bias indexes. As before, none of the three trait measures showed significant associations with the accuracy index. For all three, however, the convergent associations of the OCQ bias index were significant: Betas were .19, .24, and .23 for the NPI, the SDE scale, and the discrepancy measure, respectively $(p s<.01)$. This pattern replicates once more the validities established in Studies 1-3, as does the nonsignificant association $(-.06)$ with the IM scale. Note that this discrepancy measure differs from that used in Study 1 in that the criterion for ability was informant ratings rather than an IQ test.

The adjustment results are reported in Table 3 . The entries in the table are the regression coefficients of the OCQ bias index (over-claiming) when used along with the OCQ accuracy index in predicting adjustment. On the basis of the Taylor and Brown (1988) hypothesis, we used one-tailed tests to evaluate the predictions. Values in the first data row indicate that over-claiming has moderate-sized associations with selfreport adjustment (first three data columns) but a nonsignificant association with informant-rated adjustment (fourth data column). Values in the second and third data rows indicate that the self-report associations remain significant even with NPI and SDE added as predictors. These last two steps are equivalent to partialing out the effects of narcissistic bias on adjustment.

\section{Discussion}

The results of Study 4 provide another replication of the basic validity results for the OCQ bias, our index of over-claiming. Once again, the tendency to over-claim shows significant associations with questionnaire indicators of personalities known for their propensity to self-enhance, namely, narcissists and self-deceptive enhancers.

The unique contribution of this study is toward the debate over the Taylor-Brown adjustment hypothesis. The relation between adjustment and over-claiming (our operationalization of self-enhancement) depended on how adjustment was measured. When evaluated by knowledgeable informants, psychological adjustment showed minimal association with overclaiming. To the extent that adjustment can be assessed by the 
Table 3. Study 4: Associations of Over-Claiming Questionnaire (OCQ) Bias Index With Four Measures of Adjustment

\begin{tabular}{lcccc}
\hline & \multicolumn{4}{c}{ Criterion variable } \\
\cline { 2 - 5 } Predictor variable & $\begin{array}{c}\text { Self-esteem } \\
(\text { RSE })\end{array}$ & $\begin{array}{c}\text { Ego-resiliency } \\
(\text { ER-89) }\end{array}$ & $\begin{array}{c}\text { Self-rated } \\
\text { adjustment }\end{array}$ & $\begin{array}{c}\text { Informant-rated } \\
\text { adjustment }\end{array}$ \\
\hline OCQ bias & $.30^{* *}$ & $.25^{* *}$ & $.21^{*}$ & -.11 \\
OCQ bias + NPI & $.22^{*}$ & $.18^{*}$ & $.15^{*}$ & .13 \\
OCQ bias + NPI and SDE & $.16^{*}$ & $.14^{*}$ & $.14^{*}$ & .11 \\
\hline$N=157$. All entries are beta regression coefficients. RSE = Rosenberg's Self-Esteem Scale; ER \\
$=$ Block's Ego-Resiliency Scale; NPI = Narcissistic Personality Inventory; SDE = Self-Deceptive \\
Enhancement scale. \\
${ }^{*} p<.05$, one-tailed ; ${ }^{* *} p<.01$, one-tailed
\end{tabular}

brief measure completed by our informants, the results indicate that well-adjusted individuals have no particular propensity for self-enhancement.

When adjustment is measured by self-report, the link with positive illusions reemerges. Over-claiming showed significant positive associations with two standard self-report measures of adjustment, namely, Rosenberg's Self-Esteem Scale and Block's Ego-Resiliency Scale. Are self-reports of adjustment credible without support from informant reports? Some writers argue yes (e.g., Brown, Dutton, \& Cook, 2001; Taylor \& Armor, 1996): A positive self-view can be seen as an inherent part of good adjustment.

In this more limited respect, then, our self-report data do support the Taylor-Brown hypothesis. At the same time, the introduction of narcissism into the regression equations showed a clear reduction in these supportive associations. This reduction supports the claim that self-report adjustment measures contain a component of narcissistic bias (Block \& Thomas, 1955; Campbell, Rudich, \& Sedikides, 2002; Paulhus, 1998). Some have described this distinction as genuine self-esteem versus defensive self-esteem (Raskin, Novacek, \& Hogan, 1991; Trzesniewski, Donellan, Robins, \& Paulhus, 2003).

However, if over-claiming is a manifestation of narcissism, it seems surprising that adding narcissism as a predictor failed to eliminate the relation between adjustment and bias. The latter association remained significant after partialing out narcissism. Apparently, individuals scoring high on self-report measures of adjustment show an independent boost in self-enhancement above and beyond that attributable to narcissism. This bias associated with "genuine self-esteem" may represent the overgeneralized cognitive confidence of successful individuals.

To readers who consider ratings by informed observers friends and family - to be the most credible measure of adjustment used in these studies, our results show minimal relation between self-enhancement bias and adjustment. Although self-enhancers may be interpersonally offensive (Colvin et al., 1995; John \& Robins, 1994; Paulhus, 1998), they are viewed by others as no better or worse adjusted than average. Other readers might argue that neither self-ratings nor informant ratings will suffice: Clinical expert judges are necessary.

\section{General Discussion}

Most observers agree that people can, and often do, exaggerate the positivity of their self-reports. There is also a growing consensus that when people self-enhance, they sometimes do so in a self-deceptive fashion and sometimes as a conscious strategy. There is little consensus, however, that a valid measure of self-enhancement is currently available. Various social desirability scales, intrapsychic measures, and discrepancy measures have all been subject to severe criticism. Much of the criticism stems from the fear that self-report self-enhancement measures, though practical, are actually measures of genuinely positive attributes. Critics have called for a concrete, objectively scored indicator of self-enhancement. In this article, we offer the over-claiming technique as an advance in this search for a practical yet objective measure.

The over-claiming technique provides an operationalization of self-enhancement that is both concrete and independent of cognitive ability. The application of signal detection formulas provides a systematic and mathematically defensible basis for separating the degree of accuracy from the degree of self-report bias. ${ }^{7}$ The indexes can be scored on a standard set of knowledge items such as the OCQ-150. Although the accuracy and bias formulas are calculated independently, they may still be correlated across individuals. It is important, therefore, to partial out accuracy before the bias index is used to predict outcome variables. This caution is one of several elements that increase our confidence in interpreting the OCQ bias index as over-claiming-a distinct operationalization of self-enhancement.

\section{Convergent Validity}

Our interpretation of the over-claiming index was supported here by four studies showing convergence with established measures of trait self-enhancement. These criteria included questionnaire measures of narcissism and self-deceptive enhancement. Because it is the best validated trait measure of self-enhancement, we used the NPI as our primary criterion. As expected, associations with the NPI were consistently positive and significant-even when the OCQ was completed under anonymous conditions where there was no demand to ap-

7 One could argue that the rate of false alarms is the most convincing measure because the foils do not exist. We obtain similar results using the false-alarm rate, but the latter score is less reliable because it is based on one fifth of the responses. The criterion bias measure exploits all of the responses and is statistically more defensible in signal detection terms. 
pear positive (Study 3). This consistent link indicates that the tendency to over-claim is not an isolated questionnaire style: It results from a deeper and broader personality syndrome. The nature of that syndrome is clarified by our finding of a consistent association with a measure of self-deceptive enhancement ${ }^{8}$ under standard administration conditions. With no audience other than the self, over-claiming is unlikely to be conscious dissimulation: Chronic over-claimers really believe their exaggerated claims of knowledge.

The validity of our over-claiming index as a measure of a trait-like tendency to self-enhance is further supported by its convergence with other relevant criteria. Study 1 showed that OCQ bias predicted the most concrete measure of self-enhancement in the current literature, namely, self-criterion discrepancy (see Colvin et al., 1995; John \& Robins, 1994). In that same study, fellow discussion group members reported that over-claimers tended to brag and otherwise behave in an egotistical fashion.

Finally, the use of over-claiming rate as an indicator of state self-enhancement is supported by its responsiveness to situational demand for self-presentation. Study 2 showed that a warning about the presence of foils reduced over-claiming. Study 3 showed that, when asked to create a positive impression, respondents showed much higher levels of over-claiming. Interestingly, in both conditions in both studies, narcissists consistently showed the highest levels of over-claiming. Even within high-demand conditions, trait differences remain influential.

\section{Discriminant Validity}

As noted above, predictions with the OCQ bias measure are always assessed after controlling for the OCQ accuracy score. Thus, discriminant validity with respect to accurate knowledge is built into the calculation of the over-claiming index. Our reporting of regression coefficients instead of raw correlations was not arbitrary but a judicious decision based on our finding that the accuracy and bias indexes suppress one another. This replicable suppressor effect is worth noting in a literature that currently disparages claims for suppressor effects (see Trzesniewski et al., 2003). In short, presentation of the raw correlations would provide misleading underestimates of the true relations of accuracy and bias with their respective criterion variables.

Our research also provides evidence about other aspects of discriminant validity. We worried that over-claiming might be confounded with traditional acquiescence variance: That is, the index might simply be catching those individuals who tend to use the high end of any rating scale they encounter (Knowles \& Condon, 1999; Wiggins, 1973). We dealt with this possibility in our preliminary study (Paulhus \& Bruce, 1990) by alternating the direction of the various OCQ topics and examining the intercorrelations. No difference in correlations was observed between topics pointed in the same direction versus topics pointed in opposite directions. Evidence from the present studies further supports that claim. The associations with the NPI (a forced-choice instrument) and discrepancy measures cannot be explained by interpreting over-claiming scores as acquiescent responding.
The IM scale (Paulhus, 1991) also failed to show any association with over-claiming under honest-response conditions. This finding supports the view that under low-demand conditions, over-claiming has a self-deceptive rather than a controlled origin. However, similar to the IM scale (Paulhus, 1984; Paulhus et al., 1995), over-claiming also tracks the degree of self-presentation across conditions differing in demand for self-presentation (see Study 3). The total over-claiming score, then, is a combination of state and trait effects.

Self-monitoring is another major contender for diagnosing self-enhancement (e.g., Graziano \& Waschull, 1995; Snyder, 1974). Our Study 1 revealed no significant association between over-claiming and Self-Monitoring Scale scores. Apparently, high self-monitors do not show the narcissists' tendency to over-claim under honest response conditions. Although they may devote attention to adjusting their impressions on others, we found no evidence that self-monitors show any narcissistic bias in self-analysis.

At the same time, this differentiation from self-monitoring may be taken as further evidence that over-claiming is not simply a conscious form of self-presentation designed to impress an audience. Unlike high self-monitors, who have to be attuned to social reality, narcissistic self-enhancers have an exaggeratedly positive self-evaluation (Paulhus, in press).

\section{Practical Advantages}

Because of several valuable features, the over-claiming index scored from the OCQ shows promise as an unobtrusive measure of self-enhancement. It can be used with or without warning respondents about the foils. ${ }^{9}$ It can be used in situations with high or low demand for self-presentation. The format is straightforward and relatively nonthreatening. There is no time pressure. In short, the over-claiming approach reduces defensiveness relative to traditional measures of self-enhancement.

The over-claiming technique can be particularly valuable in a context where measurement of cognitive ability is also needed. In another report (Paulhus \& Harms, in press), we detailed four studies supporting the ability of the OCQ accuracy index to predict standard intelligence measures. This secondary feature has motivated our current plans to test the efficacy of the OCQ in practical situations such as educational assessment, personnel selection, and clinical diagnosis.

The complexities of calculating signal detection indexes can also be avoided by an alternative scoring procedure. One can use the false-alarm rate as the index of over-claiming if the hit rate is partialed out. For example, the raw correlation between false-alarm rate and self-esteem in Study 4 is . 17 but improves to .26 when hit rate is partialed out. This approach also provides a conceptual advantage in that false-alarm rate is a more intuitively compelling operationalization of over-claiming. ${ }^{10}$

\section{Theoretical Interpretations of Over-Claiming}

There are limitations incurred by our operationalization of self-enhancement as over-claiming. First is the fact that selfenhancement is measured only in the knowledge domain. Second is the potential confusion created by the fact that accuracy 
and bias are typically assumed to be mutually exclusive: In signal detection, they are independent. Therefore, one can be both accurate and biased. For example, an individual with accurate knowledge of literary authors may still over-claim by assuming that he or she recognizes even vaguely familiar foils. The apparent paradox created by independent accuracy and bias indexes might be more palatable to some readers if the indexes were relabeled knowledge and confidence, respectively. Unfortunately, the term overconfidence is precluded because it is prominent in the decision-making literature where it has been operationalized rather differently (e.g., Stankov \& Crawford, 1996).

\section{Agentic Versus Communal Self-Enhancement}

People can self-enhance with regard to a variety of dimensions. Rather than being infinite in number, the dimensions have been shown to converge into two factors variously distinguished as egotism versus morality or agency versus communion, among other labels (Campbell et al., 2002; Paulhus \& John, 1998; Raskin et al., 1991). The evidence provided in the present studies suggests that over-claiming is agentic in nature.

Support for this proposition emerges first in Study 1, where over-claiming correlated with discrepancy self-enhancement only on intelligence, Extraversion, and Openness, the most agentic traits. Over-claiming also correlated most clearly with questionnaire measures of bias known to be associated with agency, namely, self-deceptive enhancement and narcissism. By contrast, over-claiming showed no association with Impression Management, Self-Deceptive Denial, or self-monitoring scales. Hence, it is distinct from the communal, moralistic form of self-favoring bias tapped by the latter measures 11 (Paulhus \& John, 1998; Wiggins, 1991). Although both SDE and NPI tap agentic bias, the NPI also shows a slight negative correlation with communal bias. The OCQ bias index seems to avoid the disagreeable aspect of self-enhancement inherent in narcissism (Leary, Bednarski, Hammon, \& Duncan, 1997; Rhodewalt \& Morf, 1995).

\section{Questionnaire Item Correlates}

To help clarify the nature of over-claiming, we identified its best item correlates of OCQ bias in ancillary analyses of the Study 4 data. On the SDE scale, the best item correlates were "I am very confident in my judgments" and "I never regret my decisions." Noting that SDE gives credit only for extreme responses, these items suggest that over-claiming is associated with over-confidence and complete lack of regret. Among NPI items, the top correlates of OCQ bias were "I find it easy to influence others," "I like to be the center of attention," and "I am an extraordinary person." These differ in kind from the SDE item correlates and, indeed, from each other: All three derive from different factors of the NPI (Emmons, 1987). Least represented in these items is the most interpersonally aversive factor, Exploitation-Entitlement (Emmons, 1987; Watson \& Morris, 1991). Together, these results suggest that our overclaiming index, like self-deceptive enhancement, avoids the disagreeable element inherent in narcissism.

Could a questionnaire self-report version of over-claiming be developed? As questionnaires, neither the SDE nor the NPI directly address intellectual overconfidence, the form most directly linked to over-claiming knowledge across a variety of domains. We suspect that the optimal questionnaire items would sound something like "I'm the smartest person I know" or "No one thinks as clearly as I do." Recall from our introduction, however, that previous self-report measures have long been available and have equally long been criticized. Hence, we are skeptical that such a quest would be fruitful.

\section{Over-Claiming Versus Discrepancy Measures of Self-Enhancement}

We argued in the introduction that the "gold standard" measure of self-enhancement was the self-criterion discrepancy measure (e.g., John \& Robins, 1994). Using NPI scores as a criterion, the OCQ bias index performed at a comparable level to the discrepancy measures. Given the practical advantages noted above-ease of administration, in particular-a case can be made for over-claiming as the method of choice.

Discrepancy measures are conceptually persuasive in that they index degree of departure from reality (scored in the desirable direction). Is over-claiming as conceptually persuasive? Operationally, a high over-claiming score represents a low threshold for claiming recognition of general knowledge items. Presumably, the low threshold derives from an exaggerated sense of familiarity. The fact that even narcissists raised their threshold in Study 2 and lowered it in Study 3 indicates some degree of control (see Krueger, 1998). However, through it all, narcissists continued to over-claim more than did nonnarcissists. The resiliency of this association convinces us that knowledge over-claiming taps self-enhancement-if only the agentic form-and that its nature is primarily self-deceptive.

\section{Future Research}

Other projects in our laboratory involve broadening the search for self-enhancing personalities. Besides narcissists and selfmonitors, other likely candidates are Machiavellians and psychopaths. ${ }^{12}$ Some writers argue that narcissists, Machiavellians, and psychopaths are equivalent personalities when measured in the normal range (McHoskey, Worzel, \& Szyarto, 1998). So far, our evidence suggests that subclinical psychopaths also show elevated levels of OCQ bias-less so than narcissists but more so than Machiavellians (Paulhus \& Williams, 2002).

Future research is required to clarify the nature of the selfenhancement captured by the OCQ over-claiming index. Is it identical to narcissism? Is it a cognitive form of narcissism? Metcalfe (1998) has argued that such self-enhancement biases are purely a function of memory organization. In contrast, Morf and Rhodewalt (2001) argued for a more motivational perspective. From a third perspective, some have argued that self-enhancement is a controllable bias, not a cognitive illusion (Krueger, 1998; Sedikides et al., 2002). Application of the overclaiming questionnaire may aid in sorting out these opposing positions. Preliminary evidence from our laboratory suggests that OCQ bias scores are partly determined by a general memory bias that is independent of narcissism (Paulhus, Williams, \& Nathanson, 2002). Therefore, the memory bias component adds noise to our measurement of over-claiming as self-enhancement.

11 Under honest response conditions, IM taps an identity as a good, moral person (Paulhus, 2002). This view is consistent with the view that impression management is more than just manipulative faking (Hogan \& Nicholson, 1988; Schlenker \& Weigold, 1989).

12 With a newly available measure (Paulhus, Hemphill, \& Hare, in press), noncriminal psychopathy can now be studied. 
A key issue in understanding over-claiming is the psychological mechanism behind the claiming of nonexistent foils. As frequent constructors of multiple-choice tests, academics know that good foils, also known as lures, are designed to snag respondents whose knowledge of a topic is only partial. Similarly, some of our foils (e.g., "cholarine") may draw the respondents who have heard of a similar-sounding term (e.g., chlorine) but not draw respondents who have never heard of this term. Indeed, some respondents may believe the item to be a typographical error. Of course, foils were retained because they "worked": That is, they helped differentiate narcissists from non-narcissists. However, we do not yet know whether interpretation of items as typos interacts with the respondent's narcissism in determining the tendency to endorse the item. Hampering solutions to these questions is the fact that systematic item-selection procedures have yet to be developed for SDA-based measures.

One approach likely to prove fruitful in clarifying overclaiming is the investigation of situational moderators. For example, ego threat may increase over-claiming as it does other forms of self-enhancement (Campbell \& Sedikides, 1999; Morf \& Rhodewalt, 2001). Our administrations can hardly be characterized as ego threatening, yet we found substantial overclaiming even in our least threatening condition-the anonymous classroom administration in Study 3. If the ego-threat hypothesis is correct, our studies may have provided only a conservative estimate of over-claiming rates. Another potential situational moderator is time pressure (e.g., Holden et al., 2001; Stricker \& Alderton, 1999).

Finally, our understanding of the type of self-enhancement indexed by over-claiming would benefit from studying associations with individual-difference measures of a similar nature: These include various subscales of the NPI (e.g., Emmons, 1987; Raskin \& Terry, 1988), alternative measures of self-enhancement (Holden \& Fekken, 1993; Krueger, 1998), differential factors of knowledge (Rolfhus \& Ackerman, 1996), and overconfidence indexes (Stankov \& Crawford, 1996). ${ }^{13}$ Of particular interest is why overconfidence indexes have failed to show personality correlates (Wright \& Phillips, 1979), whereas our over-claiming indexes show such coherent and robust personality correlates.

\section{Conclusions}

Attempts to measure self-enhancement have always been hotly contested. Such concern is appropriate because of the critical importance of self-enhancement to fundamental psychological questions. Can we believe what people tell us? Is it a good thing or a bad thing to lie to oneself? It has become clear that neither of these questions has a simple answer. The research presented here does support our optimism that the over-claiming approach can help cut through some of the current obstacles to resolving these fundamental issues.

\section{References}

Alicke, M. D. (1985). Global self-evaluation as determined by the desirability and controllability of trait adjectives. Journal of Personality and Social Psychology, 49, 1621-1630.
Alicke, M. D., Klotz, M. L., Breitenbecher, D. L., Yurak, T. J., \& Vredenburg, D. S. (1995). Personal contact, individuation, and the betterthan-average effect. Journal of Personality and Social Psychology, 68, 804-825.

Baer, R. A., Rinaldo, J. C., \& Berry, D. T. G (in press). Response distortions in self-report assessment. In R. Fernandez-Ballesteros (Ed.), Encyclopedia of psychological assessment. London: Sage.

Block, J. (1965). The challenge of response sets. New York: Century.

Block, J. (1989). A revised Ego-Resiliency Scale (ER-89).Unpublished manuscript [test instrument], University of California, Berkeley.

Block, J., \& Kremen, A. (1996). IQ and ego-resiliency: Conceptual and empirical connections and separateness. Journal of Personality and Social Psychology, 70, 349-361.

Block, J., \& Thomas, H. (1955). Is satisfaction with self a measure of adjustment? Journal of Abnormal and Social Psychology, 51, 254-259.

Bonanno, G. A., Field, N. P., Kovacevic, A., \& Kaltman, S. (2002). Selfenhancement as a buffer against extreme adversity: Civil war in Bosnia and traumatic loss in the United States. Personality and Social Psychology Bulletin, 28, 184-196.

Bond, M. H., Kwan, V. S. Y., \& Li, C. (2000). Decomposing a sense of superiority: The differential social impact of self-regard and regard for others. Journal of Research in Personality, 34, 537-553.

Brown, J. D. (1986). Evaluations of the self and others: Self-enhancing biases in social judgments. Social Cognition, 4, 353-376.

Brown, J. D., Dutton, K. A., \& Cook, K. E. (2001). From the top down: Self-esteem and self-evaluation. Cognition and Emotion, 15, 615-631.

Campbell, W. K., Rudich, E. A., \& Sedikides, C. (2002). Narcissism, self-esteem, and the positivity of self-views. Personality and Social Psychology Bulletin, 28, 358-368.

Campbell, W. K., \& Sedikides, C. (1999). Self-threat magnifies the selfserving bias: A meta-analytic integration. Review of General Psychology, 3, 23-43.

Colvin, C. R., Block, J., \& Funder, D. C. (1995). Overly positive selfevaluations and personality: Negative implications for mental health. Journal of Personality and Social Psychology, 68, 1152-1162.

Crowne, D. P., \& Marlowe, D. A. (1964). A new scale of social desirability independent of psychopathology. Journal of Consulting Psychology, 24, 349-354.

Edwards, A. L. (1957). The social desirability variable in personality assessment and research. New York: Dryden Press.

Edwards, J. R. (1995). Alternatives to difference scores as dependent variables in the study of congruence in organizational research. Organizational Behavior and Human Decision Processes, 64, 307-324.

Emmons, R. A. (1987). Narcissism: Theory and measurement. Journal of Personality and Social Psychology, 52, 11-17.

Funder, D. C. (1995). On the accuracy of interpersonal judgments: A realistic approach. Psychological Review, 102, 652-670.

Funder, D. C., \& Colvin, R. (1997). Congruence of others' and selfjudgments of personality. In R. Hogan, J. Johnson, \& S. R. Briggs (Eds.), Handbook of personality psychology (pp. 617-647). San Diego: Academic Press.

Gangestad, S. W., \& Snyder, M. (2000). Self-monitoring: Appraisal and reappraisal. Psychological Bulletin, 126, 530-555.

Gosling, S., John, O. P., Craik, K. H., \& Robins, R. W. (1998). Do people know how they behave? Self-reported act frequencies compared with on-line codings by observers. Journal of Personality and Social Psychology, 74, 1337-1349.

Graziano, W. G., \& Waschull, S. B. (1995). Social development and selfmonitoring. In N. Eisenberg (Ed.), Social development (pp. 233-260). Thousand Oaks, CA: Sage.

Gulliksen, H. (1967). Theory of mental tests. New York: Wiley.

13 Although conceptually similar, overconfidence is operationalized differently from SDT response bias: The former is the tendency to overestimate the probability of getting an answer correct (Lichtenstein \& Fischoff, 1977). 
Hirsch, E. D. (1988). Cultural literacy. New York: Vintage.

Hofstee, W. K. (1994). Who should own the definition of personality? European Journal of Personality, 8, 149-162.

Hogan, R., \& Nicholson, R. A. (1988). The meaning of personality test scores. American Psychologist, 43, 621-626.

Holden, R. R. (1997, June). Studying faking on personality tests: Statistical and research design issues. Paper presented at the annual convention of the Canadian Psychological Association, Toronto, Ontario, Canada.

Holden, R. R., \& Fekken, G. C. (1993). Can personality test item response latencies have construct validity? Issues of reliability and convergent and discriminant validity. Personality and Individual Differences, 15, 243-248.

Holden, R. R., Wood, L. L., \& Tomashewski, L. (2001). Do response time limitations counteract the effect of faking on personality inventory validity? Journal of Personality and Social Psychology, 81, 160-169.

Horn, J. L., \& Cattell, R. B. (1966). Refinement and test of the theory of fluid and crystallized intelligence. Journal of Educational Psychology, $57,253-270$.

Humphreys, L. G., \& Swets, J. A. (1991). Comparison of predictive validities measured with biserial correlations and ROCs of signal detection theory. Journal of Applied Psychology, 76, 316-321.

John, O. P, \& Robins, R. W. (1994). Accuracy and bias in self-perception: Individual differences in self-enhancement and the role of narcissism. Journal of Personality and Social Psychology, 66, 206-219.

John, O. P., \& Srivastava, S. (1999). The Big Five trait taxonomy: History, measurement, and theoretical perspectives. In L. A. Pervin \& O. P. John (Eds.), Handbook of personality (pp. 102-138). New York: Guilford Press.

Kenny, D. A. (1994). Interpersonal perception: A social relations analysis. New York: Guilford Press.

Knowles, E. S., Coker, M. C., Scott, R. A., Cook, D. A., \& Neville, J. W. (1996). Measurement-induced improvement in anxiety: Mean shifts with repeated assessment. Journal of Personality and Social Psychology, 71, 352-363.

Knowles, E. S., \& Condon, C. A. (1999). Why people say “yes": A dualprocess theory of acquiescence. Journal of Personality and Social Psychology, 77, 379-386.

Krueger, J. (1998). Enhancement bias in descriptions of self and others. Personality and Social Psychology Bulletin, 24, 505-516.

Kwan, V. S. Y, John, O. P., Kenny, D. A., Bond, M. H., \& Robins, R. $W$. (in press). Reconceptualizing individual differences in self-enhancement bias: An interpersonal approach. Psychological Review.

Leary, M. R. (1995). Self-presentation: Impression management and interpersonal behavior. Madison, WI: Brown \& Benchmark.

Leary, M. R., Bednarski, R., Hammon, D., \& Duncan, T. (1997). Blowhards, snobs, and narcissists: Interpersonal reactions to excessive egotism. R. M. Kowalski (Ed.), Aversive interpersonal behaviors (pp. 111131). New York: Plenum Press.

Lerner, J. S., \& Tetlock, P. E. (1999). Accounting for the effects of accountability. Psychological Bulletin, 125, 255-275.

Lichtenstein, S., \& Fischoff, B. (1977). Calibration of probabilities: Do those who know more also know more about how much they know? Organizational and Human Performance, 20, 159-183.

Macmillan, N. A., \& Creelman, C. D. (1991). Detection theory: A user's guide. New York: Cambridge.

McCrae, R. R., \& Costa, P. T. (1983). Social desirability scales: More substance than style. Journal of Clinical and Consulting Psychology, $51,882-888$.

McCrae, R. R., \& Costa, P. T. (1987). Validation of the five-factor model of personality across instruments and observers. Journal of Personality and Social Psychology, 52, 81-90.

McHoskey, J. W., Worzel, W., \& Szyarto, C. (1998). Machiavellianism and psychopathy. Journal of Personality and Social Psychology, 74, 192-210.
McKelvie, S. J. (1989). The Wonderlic Personnel Test: Reliability and validity in an academic setting. Psychological Reports, 65, 161-162.

Metcalfe, J. (1998). Cognitive optimism: Self-deception or memorybased processing heuristics? Personality and Social Psychology Review, 2, 100-110.

Morf, C. C., \& Rhodewalt, F. (2001). Unraveling the paradoxes of narcissism: A dynamic self-regulatory processing model. Psychological Inquiry, 12, 177-196.

Paulhus, D. L. (1984). Two-component models of socially desirable responding. Journal of Personality and Social Psychology, 46, 598-609.

Paulhus, D. L. (1991). Measurement and control of response bias. In J. P. Robinson, P. R. Shaver, \& L. S. Wrightsman (Eds.), Measures of personality and social psychological attitudes (pp. 17-59). San Diego, CA: Academic Press.

Paulhus, D. L. (1998). Interpersonal and intrapsychic adaptiveness of trait self-enhancement: A mixed blessing? Journal of Personality and Social Psychology, 74, 1197-1208.

Paulhus, D. L. (2002). Socially desirable responding: The evolution of a construct. In H. I. Braun, D. N. Jackson, \& D. E. Wiley (Eds.), The role of constructs in psychological and educational measurement (pp. 49-69). Mahwah, NJ: Erlbaum.

Paulhus, D. L. (in press). Self-presentation measurement. In J. Ballesteros (Ed.), Encyclopedia of psychological assessment. London: Sage Publications.

Paulhus, D. L., \& Bruce, N. (1990, June). Validation of the OCQ: A preliminary study. Paper presented at the annual convention of the $\mathrm{Ca}$ nadian Psychological Association, Ottawa, Ontario, Canada.

Paulhus, D. L., Bruce, M. N., \& Trapnell, P. D. (1995). Effects of selfpresentation strategies on personality profiles and their structure. Personality and Social Psychology Bulletin, 21, 100-108.

Paulhus, D. L., \& Harms, P. D. (in press). Measuring cognitive ability via self-reported knowledge. Intelligence.

Paulhus, D. L., Hemphill, J. A., \& Hare, R. D. (in press). Self-Report Psychopathy Scale (SRP-III). Buffalo, NY $\backslash$ Toronto, Ontario, Canada: Multi-Health Systems.

Paulhus, D. L., \& John, O. P. (1998). Egoistic and moralistic bias in selfperceptions: The interplay of self-deceptive styles with basic traits and motives. Journal of Personality, 66, 1024-1060.

Paulhus, D. L., Lysy, D., \& Yik, M. S M. (1998). Self-report measures of intelligence: Are they useful as proxy measures of IQ? Journal of Personality, 66, 525-554.

Paulhus, D. L., \& Petrusic, W. (2002). Application of signal detection analysis to the measurement of individual differences. Manuscript submitted for publication.

Paulhus, D. L., \& Reid, D. B. (1991). Enhancement and denial in socially desirable responding. Journal of Personality and Social Psychology, 60, 307-317.

Paulhus, D. L., \& Williams, K. M. (2002). The dark triad of personality: Machiavellianism, narcissism, and psychopathy. Journal of Research in Personality, 36, 556-568.

Paulhus, D. L., Williams, K. M., \& Nathanson, C. (2002). The nature of overclaiming: Memory bias or self-enhancement? Unpublished manuscript, University of British Columbia, Vancouver, British Columbia, Canada.

Phillips, D. L., \& Clancy, K. J. (1972). Some effects of "social desirability" in survey studies. American Journal of Sociology, 77, 921-940.

Piedmont, R. L., McCrae, R. R., Riemann, R., \& Angleitner, A. (2000). On the invalidity of validity scales: Evidence from self-reports and observer ratings in volunteer samples. Journal of Personality and Social Psychology, 78, 582-593.

Randall, D. M., \& Fernandes, M. F. (1991). The social desirability response bias in ethics research. Journal of Business Ethics, 10, 805-817.

Raskin, R., \& Hall, C. S. (1979). A Narcissistic Personality Inventory. Psychological Reports, 45, 590. 
Raskin, R. N., Novacek, J., \& Hogan, R. T. (1991). Narcissism, self-esteem, and defensive self-enhancement. Journal of Personality, 59, 19-38.

Raskin, R. N., \& Terry, H. (1988). A principal-components analysis of the Narcissistic Personality Inventory and some further evidence of its construct validity. Journal of Personality and Social Psychology, $54,890-902$.

Rhodewalt, F., \& Morf, C. C. (1995). Self and interpersonal correlates of the Narcissistic Personality Inventory: A review and new findings. Journal of Research in Personality, 29, 1-23.

Roberts, B. W., \& Robins, R. W. (2000). Broad dispositions, broad aspirations: The intersection of personality and major life goals. Personality and Social Psychology Bulletin, 26, 1284-1296.

Robins, R. W., \& Beer, J. (2001). Positive illusions about the self: Their correlates and consequences. Journal of Personality and Social Psychology, 80, 340-352.

Robins, R. W., \& John, O. P. (1997). Effects of visual perspective and narcissism on self-perception: Is seeing believing? Psychological Science, 8, 37-42.

Rolfhus, E. L., \& Ackerman, P. L. (1996). Self-report knowledge: At the crossroads of ability, interest, and personality. Journal of Educational Psychology, 88, 174-188.

Rosenberg, S. (1965). Society and the adolescent self-image. Princeton, NJ: Princeton University Press.

Rosenthal, R., \& Rosnow, R. L. (1991). Essentials of behavioral research: Methods and data analysis (2nd ed.). New York: McGraw-Hill.

Schlenker, B. R., \& Weigold, M. F. (1989). Self-identification and accountability. In R. A. Giacalone \& P. Rosenfeld (Eds.). Impression management in the organization (pp. 21-43). Hillsdale, NJ: Erlbaum.

Schmidt, F. L. (1985). Review of the Wonderlic Personnel Test. In J. V. Mitchell (Ed.), The ninth mental measurements yearbook (pp. 17551757). Lincoln, NE: Buros Institute of Mental Measurement.

Schoenfeldt, L. F. (1985). Review of the Wonderlic Personnel Test. Ninth mental measurements yearbook (pp. 1757-1758). Lincoln, NE: Buros Institute of Mental Measurement

Sedikides, C., Herbst, K. C., Hardin, D. P., \& Dardis, G. J. (2002). Accountability as a deterrent to self-enhancement: The search for mechanisms. Journal of Personality and Social Psychology, 83, 592-605.

Sinha, R. R., \& Krueger, J. (1998). Idiographic self-evaluation and bias. Journal of Research in Personality, 32, 131-155.

Snyder, M. (1974). Self-monitoring of expressive behavior. Journal of Personality and Social Psychology, 30, 526-537.
Stankov, L., \& Crawford, J. D. (1996). Confidence judgments in studies of individual differences. Personality and Individual Differences, 21, 971-976.

Stanovich, K. E., \& Cunningham, A. E. (1992). Studying the consequences of literacy within a literate society: The cognitive correlates of print exposure. Memory and Cognition, 20, 51-68.

Stricker, L. J., \& Alderton, D. L. (1999). Using response latency measures for biographical inventory. Military Psychology, 11, 169-188.

Swets, J. A. (1964). Signal detection and recognition by human observers. New York: Wiley.

Taylor, S. E., \& Armor, D. A. (1996). Positive illusions and coping with adversity. Journal of Personality, 64, 873-898.

Taylor, S. E., \& Brown, J. D. (1988). Illusion and well-being: A social psychological perspective on mental health. Psychological Bulletin, $116,21-27$.

Trzesniewski, K. H., Donnellan, M. B., Robins, R. W., \& Paulhus, D. L. (2003, February). The antisocial individual: The negative consequences of low self-esteem and narcissism. Paper presented at the annual conference of the Society for Personality and Social Psychology, Los Angeles.

Watson, P. J., \& Morris, R. J. (1991). Narcissism, empathy, and social desirability. Personality and Individual Differences, 12, 575-579.

Wiggins, J. S. (1959). Interrelationships among MMPI measures of dissimulation under standard and social desirability instructions. Journal of Consulting Psychology, 23, 419-427.

Wiggins, J. S. (1973). Personality and prediction: Principles of personality assessment. Reading MA: Addison-Wesley.

Wiggins, J. S. (1991). Agency and communion as conceptual coordinates for the understanding and measurement of interpersonal behavior. In W. Grove \& D. Cicchetti (Eds.), Thinking clearly about psychology: Essays in honor of Paul Meehl (Vol. 2, (pp. 89-113). Minneapolis: University of Minnesota Press.

Wonderlic, E. F. (1977). Wonderlic Personnel Test manual. Northfield, IL: Wonderlic \& Associates.

Wonderlic, E. F. (1992). Wonderlic Personnel Test and Scholastic Level Exam user's manual. Libertyville, IL: Wonderlic Personnel Tests, Inc.

Wright, G. N., \& Phillips, L. D. (1979). Personality and probabilistic thinking. British Journal of Psychology, 70, 295-303.

Zumbo, B. (1999). The simple difference score as an inherently poor measure of change: Some reality, much mythology. Advances in Social Science Methodology, 5, 269-304. 


\section{Appendix}

Format of the Over-Claiming Questionnaire (OCQ)

Using the following scale as a guideline, write a number from 0 to 6 beside each item to indicate how familiar you are with it

Never heard of it

Physical Sciences

Manhattan Project

cholarine

alloy

ultra-lipid

nebula
1 asteroid

atomic number

plate tectonics

centripetal force

particle accelerator
Very familiar

4

5

6

Note. Of the 15 items above, the following 3 are foils: cholarine, ultra-lipid, and plates of parallax. Other topic categories include literature, art, history, social science, language, contemporary culture, and consumer products. nuclear fusion photon

plates of parallax satellite hydroponics 